\title{
Disturbance alters relationships between soil carbon pools and aboveground vegetation attributes in an anthropogenic peatland in Patagonia
}

\author{
Javier Lopatin ${ }^{1}$, Rocío Araya-Lopéz ${ }^{2}$, Mauricio Galleguillos ${ }^{3}$, and Jorge Perez ${ }^{3}$ \\ ${ }^{1}$ Universidad Adolfo Ibáñez \\ ${ }^{2}$ Deakin University \\ ${ }^{3}$ Universidad de Chile
}

June 16, 2021

\begin{abstract}
1 Vegetation attributes derived from species and plant functional types (PFTs) directly or indirectly drive the carbon (C) cycle in peatlands. However, anthropogenic-based disturbances may alter petland soil-plant interactions and their ability to sequester carbon. Likewise, it is unclear how the soil-plant linkages among different soil C decomposition-based pools and plant attributes vary under disturbance conditions. 2 We aimed to assess how anthropogenic disturbances affect the relationships between aboveground vegetation attributes and belowground $\mathrm{C}$ pools in a peatland located in Northern Patagonia, Chile. We further evaluated if attributes derived from PFTs are better suited to predict soil C pools than attributes derived from species. We used structural equation modeling and regression analyses to explore these differences. 3 We found that undisturbed peatland has more soil-plant significant relationships between soil $\mathrm{C}$ pools and vegetation attributes, yielding higher predictive accuracies than disturbed areas. The species-based attributes yielded consistently better results predicting soil $\mathrm{C}$ pools than PFT-based attributes. However, PFT-based information showed significant interactions with the highly-decomposed C pools in the undisturbed peatland. Likewise, plant height and diversity were only significant with $\mathrm{C}$ pools in the undisturbed peatland. 4 We observed that water-logged plant communities have different soil-plant interactions than dryer communities. These differences were observed in both areas but were higher in the disturbed peatland, making it impossible to find meaningful soil-plant relationships across vegetation types and taxa. 5 Our results highlight the importance of accounting for disturbance or management when linking vegetation attributes to soil $\mathrm{C}$ pools in peatlands. This implies that up-to-date extensive monitoring of peatland disturbances is needed to accurately monitor soil $\mathrm{C}$ attributes at the regional level using vegetation as proxies. We also need to aggregate species into specific plant functional types that hold these soil-plant interactions across landscapes, regions, and disturbances to generalize the soil-plant relationships accurately.
\end{abstract}

\section{Hosted file}

Peatland-managements_EAE.docx available at https://authorea.com/users/420080/articles/526460disturbance-alters-relationships-between-soil-carbon-pools-and-aboveground-vegetationattributes-in-an-anthropogenic-peatland-in-patagonia 